\title{
An Intelligent Auto-Tracking Vehicle
}

\author{
Ms. Ritika Dhabalia, Ms. Kritika Dhabalia \\ Research Scholar, Shri Rawatpura Sarkar Group of Institutions, Raipur, India \\ ritikadhabalia@gmail.com
}

\begin{tabular}{|c|c|}
\hline Article History & Abstract \\
\hline $\begin{array}{c}\text { Article Submission } \\
28 \text { January } 2012 \\
\text { Revised Submission } \\
27 \text { April } 2012 \\
\text { Article Accepted } \\
5 \text { May } 2012 \\
\text { Article Published } \\
\text { 30 June } 2012\end{array}$ & $\begin{array}{l}\text { With gas prices at historic highs and fuel-efficient cars in vogue, the time might be } \\
\text { perfect to introduce the Smart Car. The chief goal of this paper is designing a smart car } \\
\text { with transportation capabilities of a traditional car. The project introduces ways of } \\
\text { making car to sense the environment and navigating on its own. The algorithm is } \\
\text { implemented using a freescale's32-bit MPC5604 microcontroller and CODEWARRIOR } \\
\text { (IDE) software. It is based on Free Ranging on Grid Technology (FROG) which uses } \\
\text { Automated Guided Vehicle Systems (AGV), which are driverless cars. An AGV is a } \\
\text { robotic device that follows marks in the floor. The fundamental requirement for this } \\
\text { smart car is to sense the given track in a most efficient and in a considerably very short } \\
\text { time. The actuators used for lateral and longitudinal control were a servo and a D.C } \\
\text { motor respectively. Thus a model car can be designed with electrical, electronic and } \\
\text { mechanical systems and can be travelled in smoother and faster way in the track by } \\
\text { electromechanical control. In such automated systems, vehicles are programmed to } \\
\text { have various features to ensure smooth car navigation, traffic signal control, cameras } \\
\text { to monitor and systems to maintain appropriate speed limits etc. Thus in future, this } \\
\text { kind of smart cars acts as an intelligent transport system. } \\
\text { Keywords- Robotic car, Free Ranging on Grid technology, } 5604 \text { microcontroller, Code } \\
\text { warrior (IDE). }\end{array}$ \\
\hline
\end{tabular}

\section{Introduction}

A Smart car is an autonomous vehicle with advanced techniques such as radar, Global Positioning System and computer aided vision. Advanced control systems present in the modern day smart cars understand the vital data to predict navigational paths avoiding obstacles and hindrance.[1] The objective is to design a model car with electrical, electronic and mechanical systems and to travel the car smoother and faster in the track by electromechanical control. There are different types of processors like 8805 which is a 8 bit processor and s12x which is a 16 bit processor and 5604 which is a 32 bit processor. More efficient smart cars are designed using 32 bit processor.[2]

\section{Proposed Smart Car System Configuration}

The dynamic control of speed and steer of a smart car is done using MPC5604B. A smart car is self-driven. It is directed by a pilot line and the car changes its direction and navigates accordingly. The conventional pilot line is a black line on a white surface. The pilot line is a continuous black line 
- The background surface is white in color

- The pilot line has a width of $2.5 \mathrm{~cm}$

- The minimum bending radius of the racing track is greater than $60 \mathrm{~cm}$

- The racing track intersects only at a crossing angle of $90^{\circ}$

The starting area is $1 \mathrm{~m}$. long. In addition, there is a black starting line $10 \mathrm{~cm}$ long at both side of the starting point. The parts of the smart car are shown in figure 2 .

1. Suspension

2. Engine Friction

3. Rear Axle

4. Chassis

5. Mechanism Ackerman

6. Servomotor

7. Front Axle

8. Battery holder

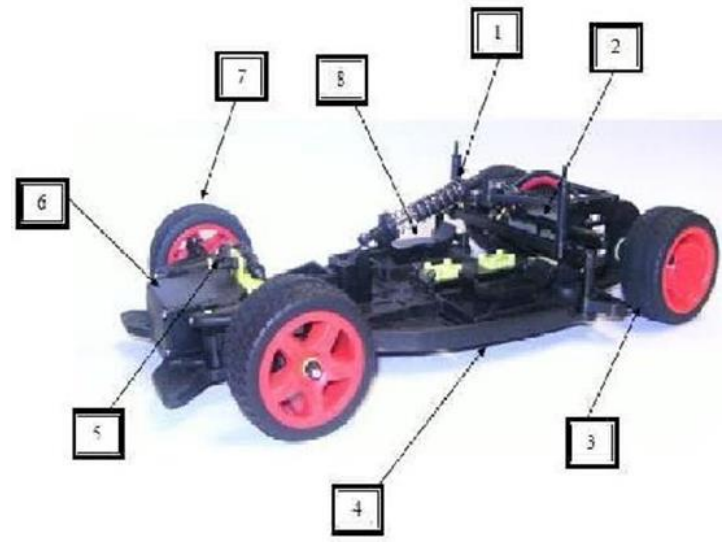

Fig 1: Parts of the Smart Car

\section{a. Rear Side}

There is a dry motor or propulsion motor which is a dc motor and it is coupled to the rear wheels and it provides dry power. These wheels are connected to the shaft which produces differential speeds.

\section{b. Front Side}

There is a dc servo motor which is connected to the front wheels for steering control. Further on the front side,there is a line sensor which senses the track.

\section{c. Line Sensor}

Automatic steering adjustment is done by sensing. Line sensor is a 128 bit sensor. It reflects as 255 or 0 by sensing the track which is of white and black color. A black strip in the center indicates the track. [3] There are 2 side strips to indicate the start position. Thus if the car deviates from the track position either towards right or towards left, it is indicated by the sensor by showing the change in the center position. Thus by identifying this, car position can be controlled.

\section{d. Electronic Board}

There is a processor board in-between the smart car. It processes the signals from the 2 motors and line sensors and gives actuating signals to steering and torque to the propulsion motor. 


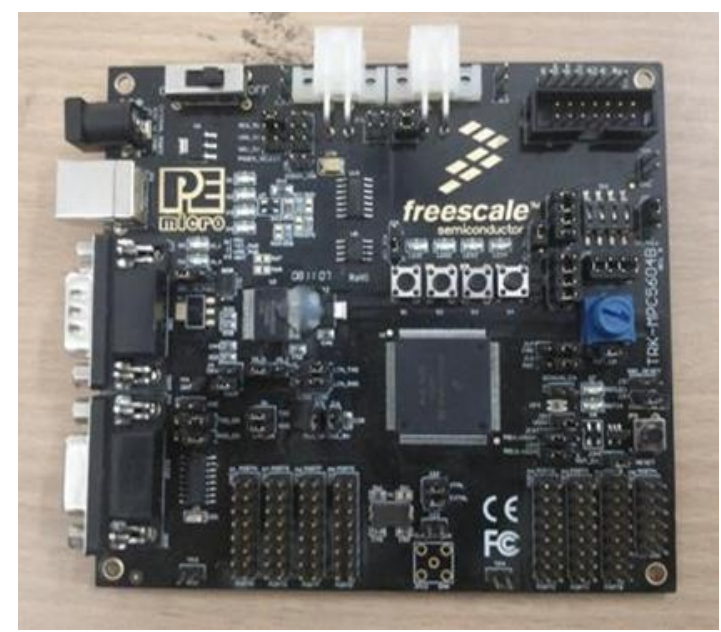

Fig 3:TRK-MPC5604B Microcontroller

Thus line sensor senses the track and sends information to the central processor (processor board). The processor board computes based on the information received from line sensor, speed sensor and it actions in giving control signals to servo motor for steering and providing necessary torque to the propulsion motor to propel vehicle at the desired speed.[4] The vehicle is powered by a rechargeable battery of $7.2 \mathrm{~V}$ that can supply up to $2000 \mathrm{~mA}$. Here there is a common shaft connected to both the wheels and there is a special differential mechanism. Here there is no common shaft and no special differential mechanism as in single propulsion motor. There is one more dc motor. So there is an additional control input from the processor board which goes into that motor.[5]

\section{Proposed Smart Car System Operation}

It is residing within microcontroller. Its main purpose is to generate pulse width modulated signals from embedded software within microcontroller. It consists of 4 MOSFETS. It is a external hardware outside microcontroller. It stops the battery voltage and applies the variable average voltage to the dc motor. It is used for steering control. Position control is needed for servo motors since it mainly concentrates on angle. Position reference is compared with the sensed position(angle) is sent to a block which is a controller and this controller is called position controller such that it makes error voltage to be zero and it makes the motor move because it generates speed reference as the output. Speed sense is obtained by the differentiation of the position is passed onto the controller called as the speed controller. The smart car model is shown in figure 2.

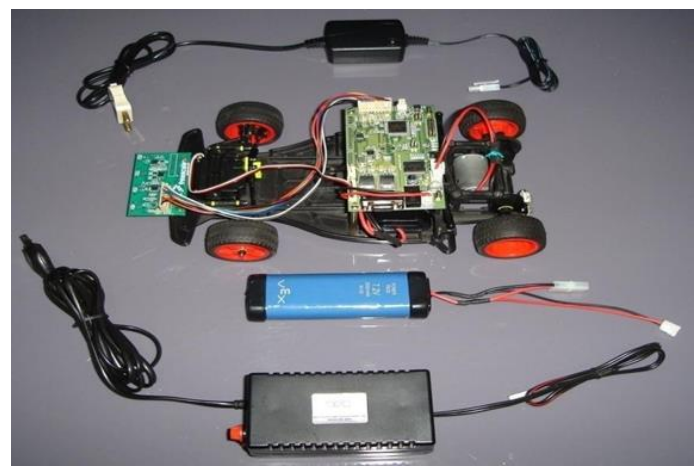

Fig 2: Model of Smart Car 
It is used for driving control. Here H-bridge is embedded in PCB and PWM is embedded as software in microcontroller. This block is called controller (PID or PD). They are the general purpose robust controllers. It deals with generation of PWM (Pulse width modulation), measurement of speed and the ways of adjusting the speed of the car.[6]

- To turn right, right wheel motor should go slow and left wheel motor should go fast.

- To turn left, left wheel motor should go slow and right wheel motor should go fast.

Thus the propulsion motor is controlled by giving proper power and torque so that the desired speed is achieved.

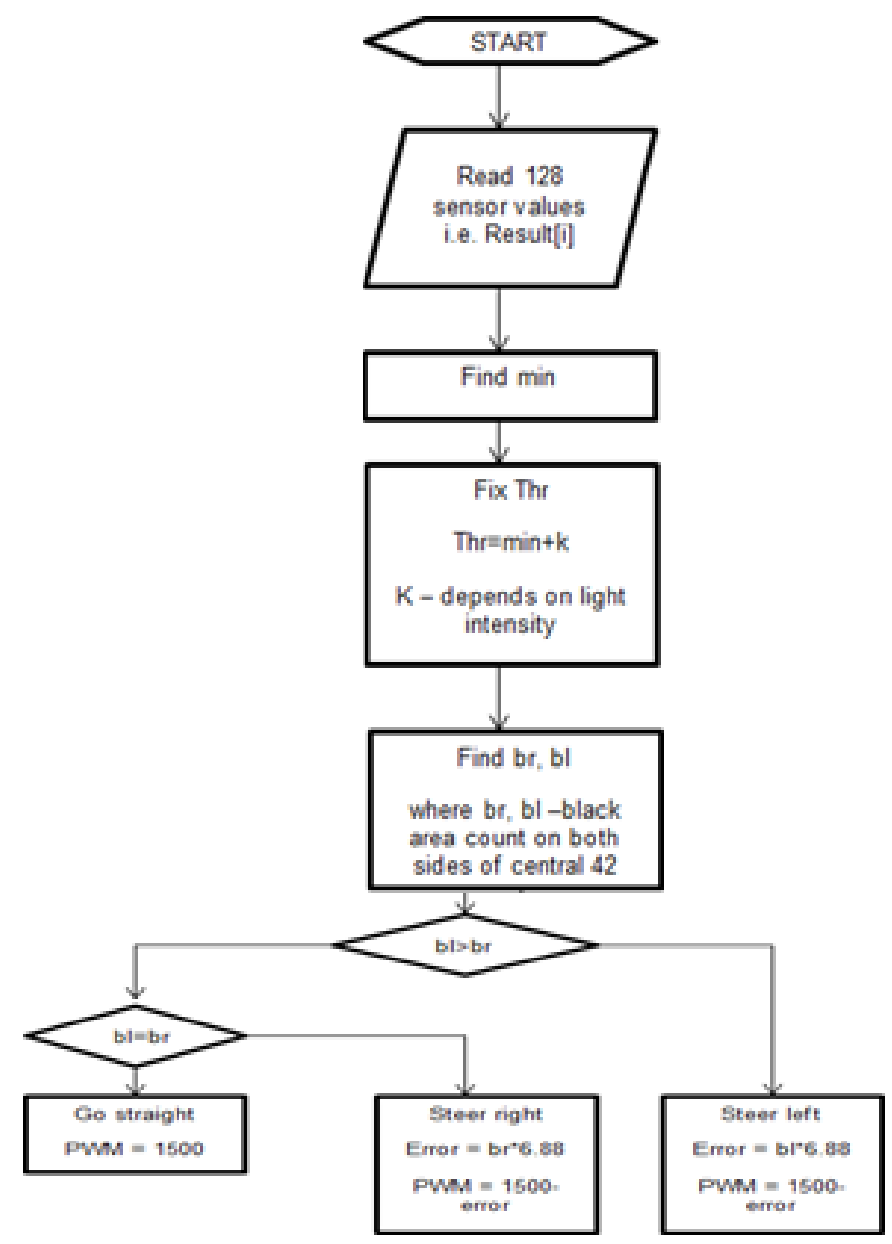

Fig 3: Flowchart showing operation of Smart Car

\section{Simulation Results \& Discussions}

The sensor is calibrated by adjusting the focal length of the camera. This is done by observing the variation of dip position according to the appropriate car position. 


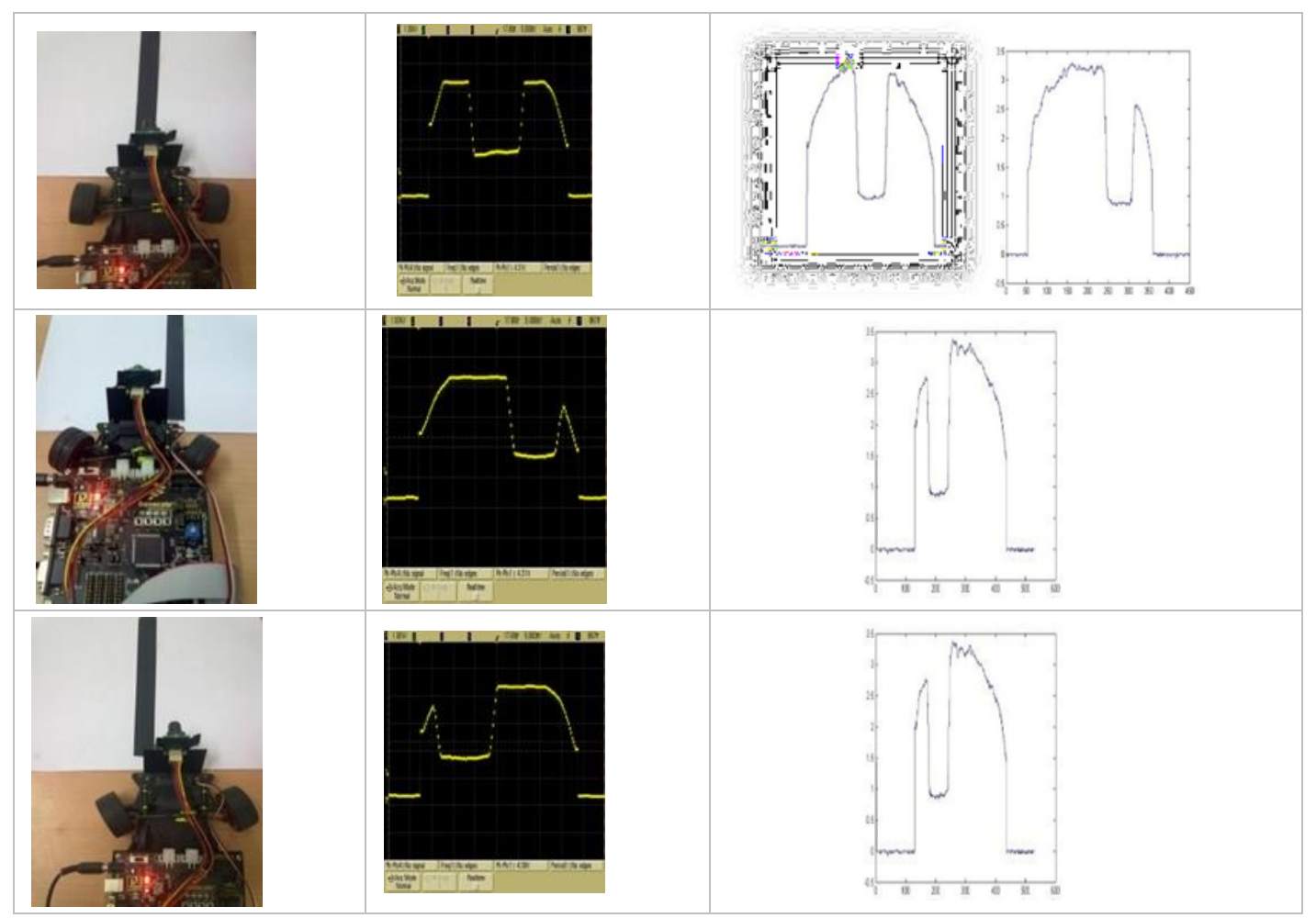

Fig 4: Sensor calibration simulation model

Reduced traffic collisions, increased reliability and decreased reaction time makes the system vital for current scenario. The roadway capacity and reduced traffic congestion leads to better traffic flow. Parking scarcity could also be reduced as cars drop down passengers and return to pick up passengers when needed. Automated guided vehicles (AGV) enlarge efficiency and diminish costs by automated activity. They find its significance in industries like paper, metals, newspaper and various manufacturing units.

The observations of PWM and steering activity are tabulated in table1

Table 1: PWM Vs Steering values

\begin{tabular}{|c|c|c|c|}
\hline Kp for steer right & Kp for steer left & PWM & Lap completion \\
\hline 8 & 7 & 160 & Did not complete \\
\hline 7.9 & 7.2 & 170 & Did not complete \\
\hline 7.6 & 7.1 & 160 & Did not complete \\
\hline 7.6 & 7.1 & 180 & Did not complete \\
\hline 7.6 & 8.1 & 185 & Did not complete \\
\hline 7.4 & 8.4 & 190 & Did not complete \\
\hline 7 & 7 & 180 & 1 min 30 sec (only left side) \\
\hline 6.9 & 7 & 170 & 1 min 10 sec (only left side) \\
\hline 6.9 & 6.9 & 160 & 1 min 10 sec (only left side) \\
\hline 6.8 & 6.9 & 200 & 1 minute (only left side) \\
\hline 7 & 6.9 & 210 & 59 seconds(both sides) \\
\hline 6.8 & 6.8 & 180 & 49 seconds(both sides) \\
\hline
\end{tabular}



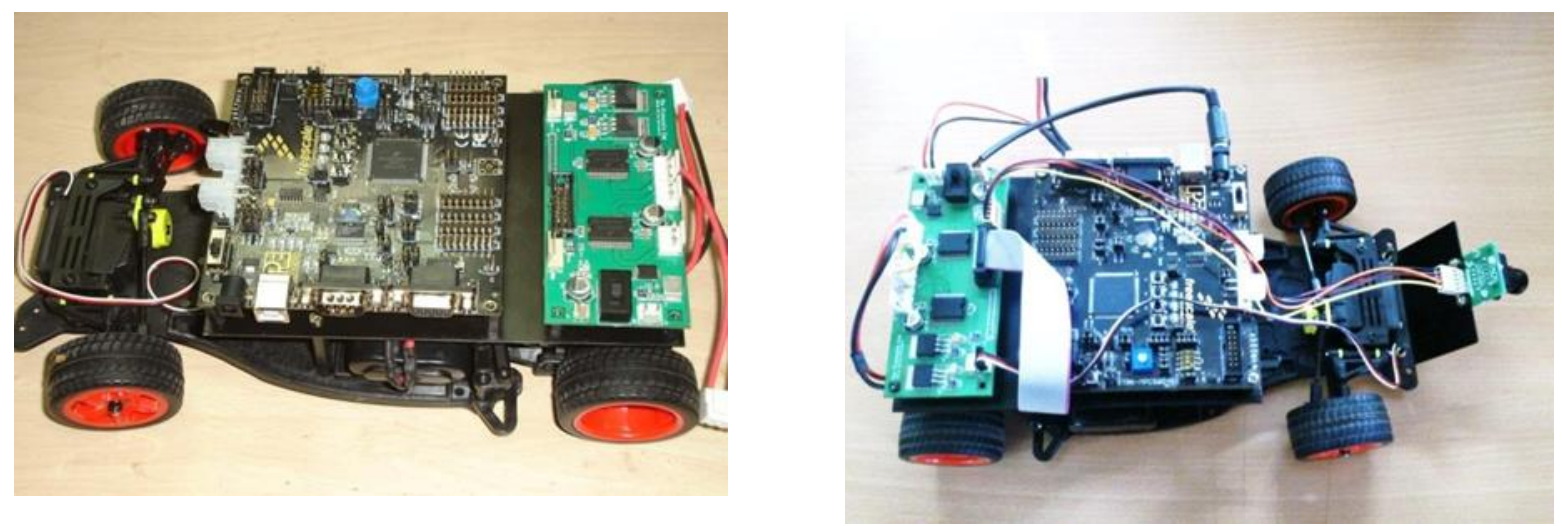

Fig 5: Fully assembled smart car with driver board

\section{Conclusion}

Thus smart car is successfully implemented and it's both hardware and software is well studied. The camera is calibrated by changing the focal length. The integration time is varied by introducing the delay. Here by implementing the algorithm, at first the smart car completes the lap in 1minute. Then by varying the speed and multiplication factor by trial and error method, the smart car is able to complete the lap in 47 seconds. Finally again by varying the speed and multiplication factor by means of trial and error method, the smart car completes the lap in 25 seconds itself.

\section{References}

[1] Hossain, S. G. M., Jamil, H., Ali, M. Y., \& Haq, M. Z. (2010, February). Automated guided vehicles for industrial logistics-Development of intelligent prototypes using appropriate technology. In 2010 The 2nd International Conference on Computer and Automation Engineering (ICCAE) (Vol. 5, pp. 237-241). IEEE.

[2] Tao, Y. F., Chen, J. R., Liu, M. H., Liu, X. X., \& Fu, Y. L. (2010, October). Research of unidirectional automated Guided Vehicles System based on simulation. In 2010 IEEE 17th International Conference on Industrial Engineering and Engineering Management (pp. 1564-1567). IEEE.

[3] Zhan, Y. D., Guo, Y. G., \& Zhu, J. G. (2011, December). Intelligent coordination steering control of automated guided vehicle. In 2011 International Conference on Applied Superconductivity and Electromagnetic Devices (pp. 204-207). IEEE.

[4] Hashimoto, N., Kato, S., Minobe, N., \& Tsugawa, S. (2007, June). Automated vehicle mobile guidance system for parking assistance. In 2007 IEEE Intelligent Vehicles Symposium (pp. 630-635). IEEE.

[5] Petriu, E. M. (1991). Automated guided vehicle with absolute encoded guide-path. IEEE transactions on robotics and automation, 7(4), 562-565.

[6] G. Kaloutsakis, N. Tsourveloudis and P. Spanoudakis, "Design and development of an automated guided vehicle," IEEE International Conference on Industrial Technology, 2003, Maribor, Slovenia, 2003, pp. 990993 Vol.2.

[7] Q. Li, A.C. Adriaansen, J.T. Udding, A.Y. Pogromsky, Design and Control of Automated Guided Vehicle Systems: A Case Study, IFAC Proceedings Volumes, Volume 44, Issue 1, 2011, Pages 13852-13857

[8] Christopher Kirsch, Christof Röhrig, Global Localization and Position Tracking of an Automated Guided Vehicle, IFAC Proceedings Volumes, Volume 44, Issue 1, 2011, Pages 14036-14041 